\title{
Impact of rolling conditions on the hydriding of grade 2 titanium welded tubes
}

La Chance LEPEMANGOYE $^{\mathrm{a}, \mathrm{b}}{ }^{\mathrm{b}}$, Nicolas CRETON ${ }^{\mathrm{b}}$, Virgil OPTASANU ${ }^{\mathrm{b}}$, Elise DELOYE ${ }^{\mathrm{a}}$, Tony MONTESIN ${ }^{\mathrm{b}}$, Jean-Jacques FUNDENBERGER ${ }^{\mathrm{c}}$, Olivier PERROUD $^{\mathrm{c}}$

${ }^{a}$ NEOTISS, ZI, rue Marthe Paris, BP 30, 21150 Venarey-Lès-Laumes, France

b Université de Bourgogne, Laboratoire ICB, UMR 6303 CNRS/UBFC, 9 Av. Alain Savary, BP 47870, 21078 Dijon, France

${ }^{\mathrm{c}}$ Université de Lorraine, Laboratoire LEM3, UMR CNRS 7239, 7 rue Félix Savart, BP 57073 Metz, France

\begin{abstract}
:
In this article, we study the impact of rolling conditions on the texture of the commercially pure titanium grade 2. In a previous work, NEOTISS in collaboration with ICB laboratory, shown that the texture highly influences the precipitation of hydrides in Titanium. In order to create different textures, Titanium sheets grade 2 are cold rolled asymmetrically and symmetrically with or without lubricant. The inverse pole figures and direct pole figures obtained allow us to deduce that symmetrical cold rolling does not change the grains orientation but generates a rotation of grains along c-axis (normal to basal plan). However, asymmetrical cold rolling leads to the formation of a new crystallographic texture, which could limit the formation of the hydrides in titanium grade 2 submitted to a hydrogen-rich environment.
\end{abstract}

Key words: asymmetrical rolling, symmetrical rolling, titanium, hydriding, texture

\section{Introduction}

Titanium owns excellent corrosion resistance, good mechanical properties, low density, tolerable castability, good weldability, and excellent biocompatibility. These properties are suitable for use in many industries such as aerospace, automotive, petrochemistry, nuclear plant, and desalination plant [1]. Titanium alloys are used to design reactors, condensers and many other technical parts of systems in the previously cited industries[2],[3]. According to their applications, titanium can be submitted to aggressive environments (temperature, pressure and gas atmospheres) and, in some particular cases, exposed to hydrogen. Those extreme conditions can lead to embrittlement of the material, and especially hydrogen embrittlement. Hydrogen has a great affinity with titanium [4]-[6], it's easily absorbed in the material and interacts strongly with titanium to form hydrides. Indeed, when hydrogen exceeds the maximum solubility in hep $\alpha$-Ti (about $0.001-0.003 \mathrm{wt}$. \% at RT [7], [8], it transforms in $\varepsilon$-TiH2 and $\gamma$-TiHx (with $1,5 \leq \mathrm{x} \leq 1,99$ ) hydrides [9]-[12]. The formation of a tetragonal TiH2 hydride has especially been reported [11], whose lattice parameters increase with increasing hydrogen content [10], [11]. Due to the difference in lattice volume of both phases [11], [13], mechanical stresses are introduced into the metal [14], [15]. As a consequence, when hydrides are present in the material, they lead to plastic strain and hardening of the material [12], [16]-[18]. The corresponding modification of mechanical and chemical properties of the material can introduce stress corrosion cracking. In this way, for many industries, it is essential to control hydrogen content in the material and its mechanical properties during service life. Thus, it is essential to understand the mechanism of hydriding and also to determine the parameters who influence the hydride presence.

In order to bring new data in the study of hydrogen dissolution within a titanium grade 2 welded tube submitted to severe use conditions, a first work was supported by NEOTISS in collaboration with the ICB laboratory [19]-[21]. The study focused on the hydrides likely to precipitate within the Ti metallic matrix. This work highlights the parameters influencing the presence of hydrides, their distribution, as well as their morphology. However, in the light of the conclusions of this work, an important question remains: how two strips with the same chemical composition, can lead to tubes presenting different capabilities to absorb hydrogen and form hydrides? The micrographs of titanium grade 2 from two different sheets (T40A and T40B) rolled on different rolling lines are shown in fig. 1 . After 500 hours under water in the autoclave at $350^{\circ} \mathrm{C}$ and 210 bars, one observes the presence of hydrides precipitates in the T40A sample and not in the T40B sample. The two samples present only one major difference: the crystallographic texture (fig.2). The (0002) pole figure of the T40B seems to reflect a shear strain appearing during the cold rolling process: such a pole figure was already observed by Wroński et al. [22] when the asymmetrically cold rolling is applied on grade 2 titanium sheets.

To operate improvements on the current manufacturing process of tubes, NEOTISS wanted to seek an answer to this question through a new research program initiated in October 2018
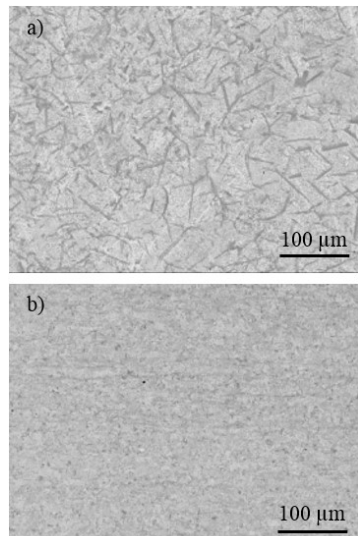

Figure 1: Micrographs of two T40 alloys sheets rolled on different rolling lines. The samples were put in an autoclave under water ( $350^{\circ} \mathrm{C}$ and $210 \mathrm{bars}$ during 500 hours). Only T40A sample (a) presents hydrides precipitates, compared with T40B sample (b) [19].

0002

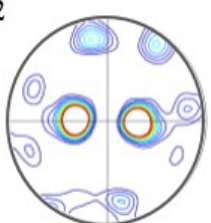

$\mathrm{T} 40 \mathrm{~A}$
0002

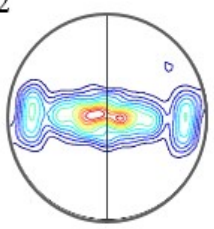

T40 B

Figure 2: (0002) pole figures of T40A and T40B samples [19].

In this article, we will present the first stage of our investigations in order to determine the most favourable rolling conditions leading to a crystallographic texture similar to that obtained on the T40B sample. In this aim, we will especially care about the effects of asymmetrical and symmetrically cold rolling on grains crystallographic orientation of CP Ti [12], [19], [22]-[24].

\section{Material and experimental procedure}

The material used in this study is a commercially pure grade 2 titanium (ASTM), provided by NEOTISS in the form of $1.24 \mathrm{~mm}$-thick rolled sheets and not in the annealed state. Its composition is given in table 1 . Strips $(200 \times 58 \times 1.24 \mathrm{~mm} 3)$ are cut from the provided rolled sheets and then cold-rolled with a laboratory's miniature roll. The maximal velocity of the rollers is $16 \mathrm{rpm}$. This rolled sheet is symmetrically (with and without lubricant) and asymmetrically cold rolled with different reduction rates. The addition of a lubricant for some samples is realized to study its potential impact on upcoming hydriding tests. Wroński et al. showed that for low to intermediate rolling reduction $(<40 \%)$, the predominant mechanism are slip and twinning, while for higher rolling reduction $(>40 \%)$ the main mechanism is only slip. Considering these observations, two reduction rates (50\% and $20 \%)$ are

(C) The Authors, published by EDP Sciences. This is an open access article distributed under the terms of the Creative Commons Attribution License 4.0 (http://creativecommons.org/licenses/by/4.0/). 
applied during cold rolling tests in order to create different rates of plastic strain mechanisms. For symmetrical cold rolling tests, we affect a roller velocity (V1) of 16 rpm. For the asymmetrical cold rolling tests, two roller velocity ratios (V lower roll/V higher roll) are applied: 1.1 and 1.3 . The bottom roll velocity is 14 rpm (V2) and 12 rpm (V3) for 1.1 and 1.3 roller velocity ratios, respectively. The top roll velocity is $16 \mathrm{rpm}$ (V1) in both cases.

All the samples are characterized using X-ray diffraction to determine the texture (direct pole figures) of the material before and after the different treatments. Using the ATEX software, we can then obtain the inverse pole figures (IPF) maps deduced from the orientation distribution functions (ODF).

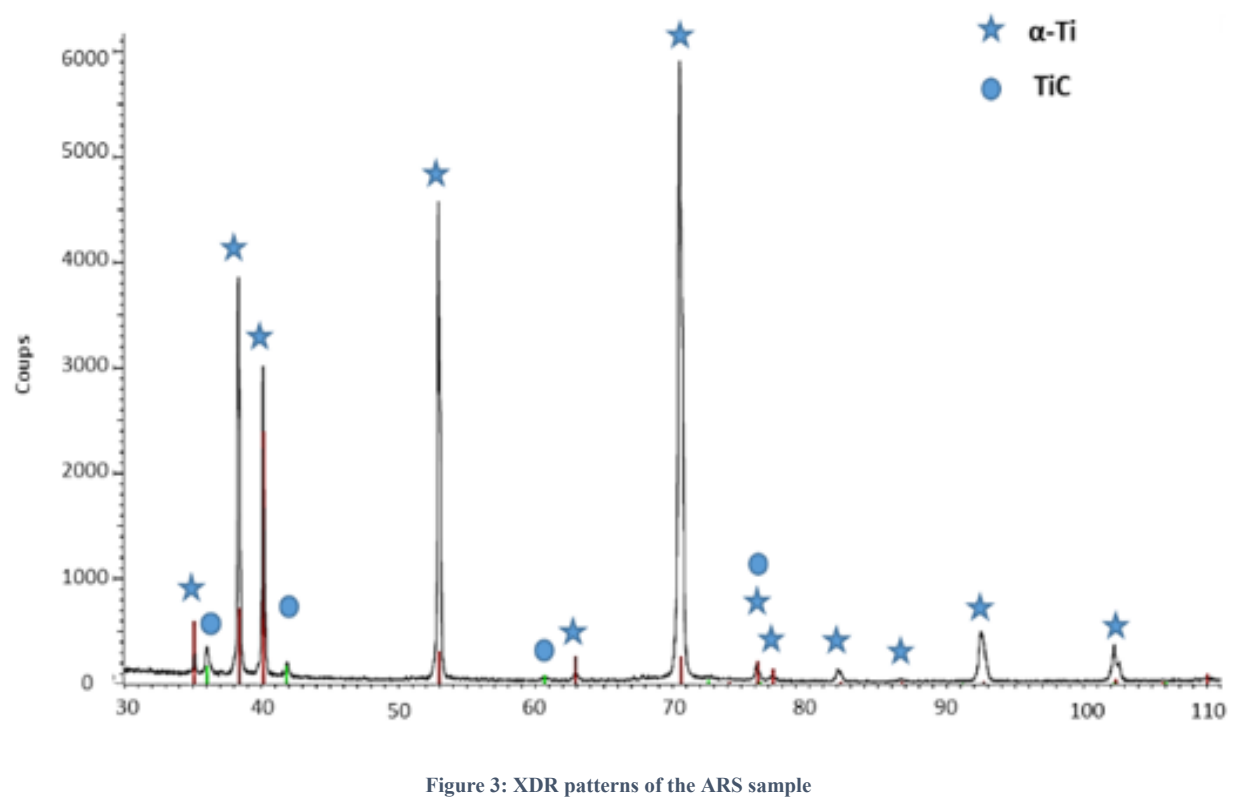

Table 1: Titanium admissible content, grade 2 quality (ASTM standard)

\begin{tabular}{ccccccc}
\hline Elements & Ti & Fe & O & N & C & H \\
Nominal content $(\% \mathrm{~m})$ & 99,2 & & & & & \\
T40 content & bal & 460 & 800 & $<20$ & 95 & 27 \\
\hline
\end{tabular}

\section{Results and discussion}

$X R D$ results of as-received sheets $(A R S)$

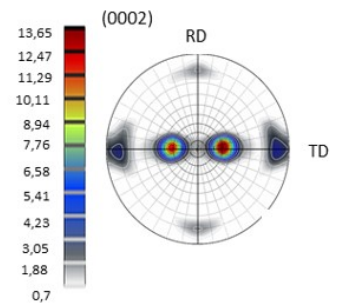

Figure 4: (0002) pole figure of the as-received commercially pure Titanium sheets

The X-ray diffraction pattern of ARS samples is shown in Figure 3. The sample is composed of a phase matrix $\alpha$-Ti and titanium carbides. The titanium lattice parameters are: a $=2,95 \AA$ and $c=4,68 \AA$. The (0002) Pole figure is presented on Fig 4. RD corresponds to the rolling direction, TD the transverse direction and ND the normal to the surface sample (normal to the stereographic projection). The most grains are oriented along the normal direction (ND) with a spread of $\pm 30^{\circ}$ toward the transverse direction (TD). The distribution is bimodal and maximal intensity is $\sim 13.65$. This figure corresponds to a classic pole figure of a hexagonal compact rolled material with a lattice parameters ration c/a $<1.633$ [25].

The figure 5.a evidences the IPF maps obtained in the three directions (RD, TD, ND) of the sample. We can see that the grains maximal intensities are located near (10 10$)$ and (11 ${ }^{-} 23$ ) respectively on $\mathrm{ND}$ and $\mathrm{RD}$ maps. We can deduce the following information:

- $\quad \mathrm{ND}$ is normal to (11-23). As a consequence, the surface sample is parallel to (11-23);

- $\quad \mathrm{RD}$ is normal to $(10-10)$ 

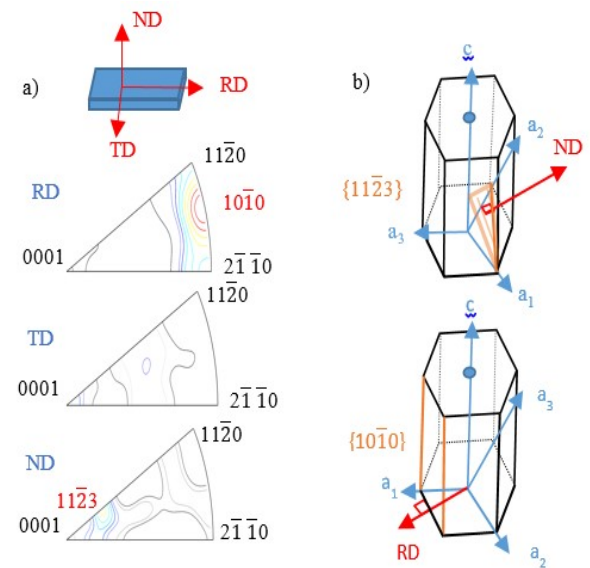

Figure 5: IPF maps in different directions of ASR (a), representation of the RD and ND orientation in the hexagonal lattice (b)

These planes and directions are illustrated in Figure 5.b thus we can deduce the orientation of the hexagonal lattice in the metal sheet. $\{11-23\}<10-10>$ is the texture of ARS.

XRD results of symmetrical cold rolling samples (SCRS)

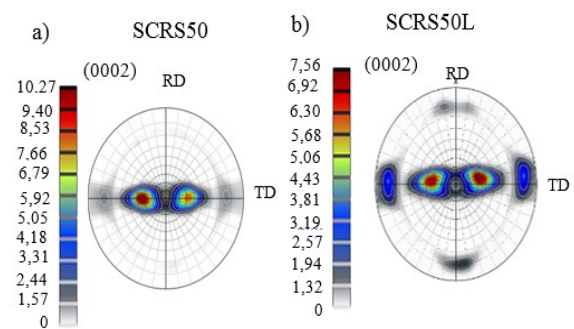

Figure 6: (0002) pole figures and ODF maps of titanium sheet symmetrically cold rolled without lubricant (a) and with lubricant (b)

The figure 6 presents the (0002) pole figures of the cold rolled sample with the reduction rate of $50 \%$, with lubricant (SCRS50L) or without (SCRS50). The most grains are oriented along the normal direction (ND) with a spread of $\pm 30^{\circ}$ toward the transverse direction (TD). Maximal intensity has slightly decreased and the distribution is always bimodal. The similar results are observed on ARS pole figure in fig 4.

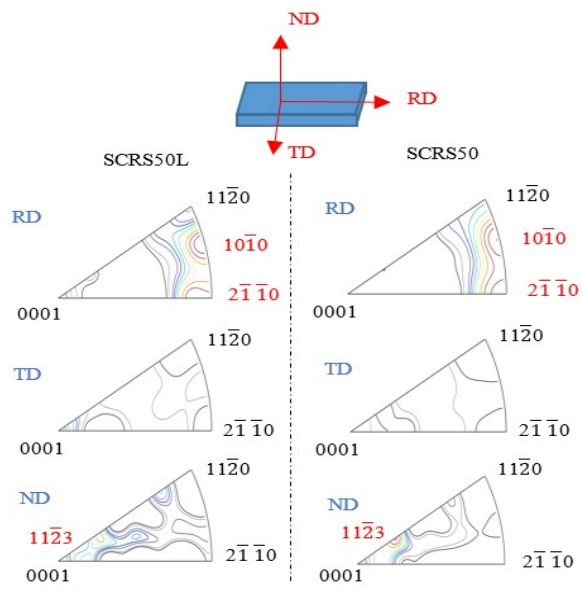

Figure 7: IPF maps of titanium sheet symmetrically cold rolled without lubricant (SCRS50) and with lubricant (SCRS50L)

IPF maps of SCRS50 and SCRS50L samples are very similar (Fig.7). On the RD map, the maximum intensities show the grains are located in (10-10) and (2-1-10). On ND map, most grains are located in (11-23). It means that:

- $\mathrm{RD}$ is normal to (10-10) and (2-1 -10),

- the sample surface is parallel to (11-23), as the ARS sample.

So, there are two possible textures. The first one corresponds to the ARS sample texture. The other one, $\{11-23\}<2-1-10>$, corresponds to a lattice rotation of the previous one along caxis. These planes and directions are illustrated in fig.8.

Through the above-mentioned analyze, we can conclude that the impact of symmetrical cold rolling (with or without lubricant) on the texture of the ARS initial sample is not significant.

We only note rotation of some grains along their c-axis. 


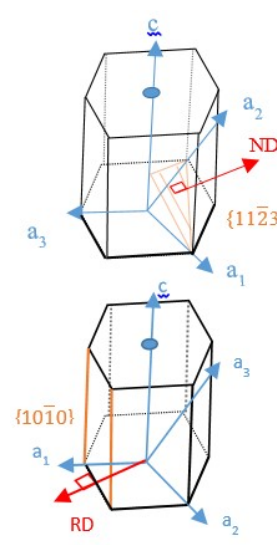

$\{11 \overline{2} 3\}<10 \overline{1} 0>$

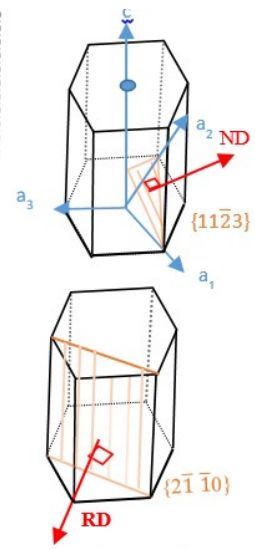

$\{11 \overline{2} 3\}<2 \overline{1} \overline{1} 0>$

Figure 8: Representation of RD and ND orientation in the hexagonal lattice for the two textures obtained after a symmetrically cold rolling with and without lubricant

XRD results of asymmetrical cold rolling samples (ACRS)

The (0002) pole figure of the ACRS with 50\% reduction rates and 1.1 velocity ratio (ACRS50-1.1) is given in figure 9 . Most of the grains have the same orientation as the ARS. In contrast, on the pole figure of the asymmetrically cold rolling sample with $20 \%$ reduction rates and 1.3 velocity ratio (ACRS20-1.3), given in figure 9 , the crystallographic orientation has changed. Most of the grains are oriented along the normal direction (ND) with a spread of $\pm 2^{\circ}$ toward the transverse direction (TD). We can say that the grains are nearly centred.

ACRS50-1.1

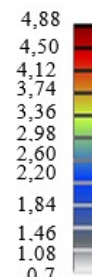

1.08
0.7

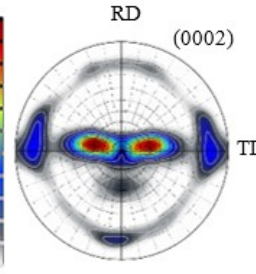

Figure 9: (0002) pole figures and ODF maps of titanium sheet asymmetrically cold rolled with a 1.1 roller velocity ratio and $50 \%$ reduce rate (ACRS50-1.1) and with a 1.3 roller velocity ratio

\section{ACRS20-1.3}

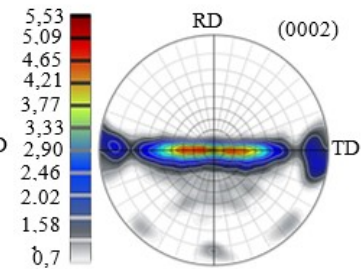
and $20 \%$ reduce rate (ACRS20-1.3)

We obtain a different texture in both cases. Indeed, on the IPF maps of the ACRS50-1.1, we can see that a majority of grains are oriented along (10-10) and (2-1 -13) (fig. 10). We can deduce that:

- $\mathrm{RD}$ is normal to (10-10),

- The surface sample is parallel to (2-1-13).

The orientations of ND and RD in hexagonal lattice after asymmetrically cold rolling are given in the figure 11.a. The new texture is $\{2-1-13\}<10-10>$. It corresponds to the rotation of hexagonal lattice around its c-axis. We find in case of symmetrical cold rolling. For ACRS20-1.3 (fig. 10), IPF maps reveal that:

- $\mathrm{RD}$ is normal to (11-20);

- $\quad \mathrm{ND}$ is normal to (0001). As a consequence, the surface sample is parallel to (0001).

The new texture obtained is $\{0001\}<11-20>$. Hexagonal lattice is positioned on its basal plane after cold rolling (figure 11.b)

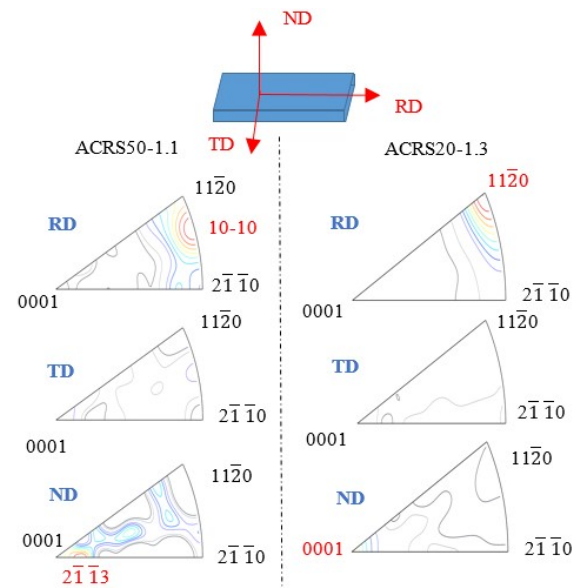

Figure 10: IPF maps of titanium sheet asymmetrically cold rolled with a 1.1 ratio and 50\% reduce rate (ACRS50-1.1) and with a 1.3 ratio and $20 \%$ reduce rate (ACRS20-1.3)

We can conclude after these analyses that asymmetrical cold rolling changes more the hexagonal lattice orientation of the ARS compared to SCRS50. Furthermore, the crystallographic orientations change according to the velocity ratios. The higher the roller speed ratio, the less the lattice hexagonal is inclined. 


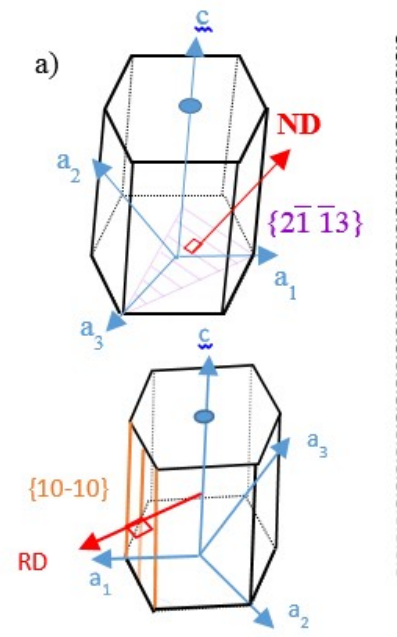

b)

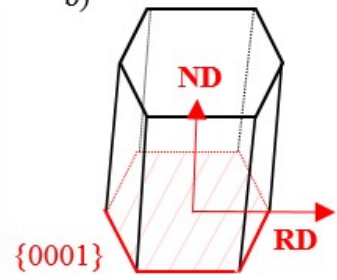

$\{0001\}<11 \overline{2} 0>$

$\{2 \overline{1} \overline{1} 3\}<10 \overline{1} 0>$

Figure 11: Representation of the ND and RD axis orientation in the hexagonal lattice and two orientations of the hexagonal lattice on sample surface after a asymmetrically cold rolling with a 1.1 roller velocity ratio and $50 \%$ reduce rate (a) and with a 1.3 roller velocity ratio and $20 \%$ reduce rate (b)

\section{Conclusions}

In this work, it was shown that symmetrical cold rolling, with and without lubricant, applied on the cold rolled titanium alloy (ASR) slightly changes the texture $(\{11-23\}<2-1-10>$ texture added to the first $\{11-23\}<10-10>$ texture). However, the inclination of hexagonal lattice against the sample surface stays identical. We only assist to a rotation of hexagonal lattice around its c-axis. The asymmetrically cold rolling changes more the texture of the ARS and modifies the hexagonal lattice orientation of the grains. The higher is the velocity ratio, the less inclined is the hexagonal lattice. We obtain a $\{2-1-13\}<10-10>$ texture for 1.1 roller velocity ration and $\{0001\}<11-20>$ texture for 1.3 roller velocity ratio after asymmetrical cold rolling.

In future tests, these ARS sample, SCRS, and ACRS will be submitted to stress corrosion cracking tests under hydrogen to highlight the impacts of the formatting conditions on the hydriding of commercially pure Titanium. Also, other technological solutions to limit the absorption of hydrogen in the material will be tested:

- Forming an oxide layer thermally or electrochemically at the surface of the material to create a barrier;

- Generating compressive stresses in the superficial layer of the material by shot peening

\section{$\underline{\text { Acknowledgements }}$}

This work was supported by the French "Inverstissements d'avenir" program, project ISITE-BFC (contract ANR-15-IDEX-0003).

\section{References}

[1] G. Lütjering et J. C. Williams, Titanium. Berlin; New York: Springer, 2003.

[2] B. D. Gélas, M. Armand, L. Séraphin, et R. Tricot, «Titane et alliages de titane », Techniques de l'ingénieur, 1976, p. 17.

[3] C. Leyens et M. Peters, Titanium and Titanium Alloys: Fundamentals and Applications. John Wiley \& Sons, 2003.

[4] V. Goltsov, « Fundamentals of hydrogen treatment of materials and its classification », International Journal of Hydrogen Energy, vol. 22, no 2-3, 1997, p. 119-124.

[5] V. A. Goltsov, « Hydrogen treatment (processing) of materials: current status and prospects », Journal of Alloys and Compounds, vol. 293-295, 1999, p. 844-857.

[6] F. H. Froes, O. N. Senkov, et J. I. Qazi, « Hydrogen as a temporary alloying element in titanium alloys: thermohydrogen processing », International Materials Reviews, vol. 49, no 3-4, 2004, p. 227-245.

[7] I. I. Phillips, P. Poole, et L. L. Shreir, « Hydride formation during cathodicpolarization of Ti-I. Effect of current density on kinetics of growth and composition of hydride », Corrosion Science, vol. 12, no 11, 1972, p. 855-866.

[8] I. I. Phillips, P. Poole, et L. L. Shreir, « Hydride formation during cathodic polarization of Ti-II. Effect of temperature and pH of solution on hydride growth », Corrosion Science, vol. 14 , no 9,1974 , p. 533-542.

[9] Ch. Borchers, A. V. Leonov, T. I. Khomenko, et O. S. Morozova, « Mechanism and kinetics of mechanically induced transformation of titanium and titanium hydride: Effect of reaction medium on microstructure, morphology and hydrogen-uptake properties », Journal of Materials Science, vol. 39, no 16/17, 2004, p. 5259-5262, 2004.

[10] D. Schur, « Phase transformations in titanium hydrides », International Journal of Hydrogen Energy, vol. 21, no 11-12, 1996, p. 1121-1124

[11] P. E. Irving et C. J. Beevers, « Some metallographic and lattice parameter observations on titanium hydride », Metallurgical Transactions, vol. 2, no 2, 1971, p. 613-615.

[12] J. Wen, N. Allain, et E. Fleury, « Hydrogen evolution and its effects on cold rolling behavior in commercial pure titanium », Materials Characterization, vol. 121, 2016, p. 139-148.

[13] V. Trefilov, « Effects of temperature change and hydrogen content on titanium hydride crystal lattice volume*1 », International Journal of Hydrogen Energy, vol. 21, no 11-12, 1996, p. 1101-1103.

[14] T. Ogawa, K. Yokoyama, K. Asaoka, et J. Sakai, « Distribution and thermal desorption behavior of hydrogen in titanium alloys immersed in acidic fluoride solutions », Journal of Alloys and Compounds, vol. 396, no 1-2, 2005, p. 269-274.

[15] E. Tal-Gutelmacher et D. Eliezer, « High fugacity hydrogen effects at room temperature in titanium based alloys », Journal of Alloys and Compounds, vol. 404-406, 2005, p. 613-616.

[16] E. Conforto, I. Guillot, et X. Feaugas, « Solute hydrogen and hydride phase implications on the plasticity of zirconium and titanium alloys: a review and some recent advances », Philosophical Transactions of the Royal Society A: Mathematical, Physical and Engineering Sciences, vol. 375, no 2098, 2017, p. 20160417.

[17] C. L. Briant, Z. F. Wang, et N. Chollocoop, « Hydrogen embrittlement of commercial purity titanium », Corrosion Science, vol. 44, no 8, 2002, p. 1875-1888.

[18] H. M. Tawancy, « On the Hydrogen Embrittlement of Commercially Pure Alpha Titanium: An Example from the Petrochemical Industry », Journal of Materials Engineering and Performance, vol. 26, no 2, 2017, p. 504-513.

[19] V. Duquesnes, «De l'hydruration du titane et ses alliages: impact des paramètres de mise en forme du matériau et conséquences sur sa durabilité en milieu corrosif », PhD Thesis, Université de Bourgogne, Dijon, France, 2016.

[20] S. Dejardin, V. Duquesnes, N. Creton, I. Bezverkhyy, R. Oltra, et T. Montesin, « Toward a study of effects on hydrogen diffusion into T40 titanium alloy », Defect and Diffusion Forum, vol. 365, 2015., p. 272-277

[21] V. Duquesnes, T. Montesin, N. Creton, S. Dejardin, et E. Deloye, «Etude expérimentale de l'impact de l'hydrogène sur le comportement thermomécanique du titane ", Traitements et Matériaux, 2016, p. 35-40.

[22] M. Wroński, K. Wierzbanowski, M. Wróbel, S. Wroński, et B. Bacroix, « Effect of rolling asymmetry on selected properties of grade 2 titanium sheet », Metals and Materials International, vol. 21, no 5, 2015, p. 805-814.

[23] Y. B. Chun, S. H. Yu, S. L. Semiatin, et S. K. Hwang, « Effect of deformation twinning on microstructure and texture evolution during cold rolling of CP-titanium », Materials Science and Engineering: A, vol. 398, no 1-2, 2005, p. 209-219.

[24] N. Liu et al., " Microstructure and textural evolution during cold rolling and annealing of commercially pure titanium sheet », Transactions of Nonferrous Metals Society of China, vol. 28, no 6, 2018, p. 1123-1131.

[25] Y. Balcaen, « Etude des mécanismes de déformation du titane T40 en formage incrémental », p. 205 